Caso 8/2005

\title{
Atriocavoplastia com tecido atrial no tratamento da comunicação interatrial tipo seio venoso superior
}

\section{Atriocavoplasty with atrial tissue in the treatment of upper sinus-venous type interatrial communication}

Ulisses Alexandre CROTI, Domingo Marcolino BRAILE, Moacir Fernandes de GODOY, Aírton Camacho MOSCARDINI

RBCCV 44205-787

\section{DADOS CLÍNICOS}

Paciente de 13 anos, masculino, branco, natural de São José do Rio Preto. Apresentou episódio de infecção pulmonar aos dois anos, evoluindo totalmente assintomático até nova internação há três meses, com quadro clínico e radiológico compatível com pneumonia. Encaminhado ao especialista, foi observado no radiograma de tórax dilatação em arco médio. BEG, acianótico, eupneico, corado. Ritmo cardíaco regular em dois tempos, desdobramento fixo da segunda bulha e sopro sistólico ejetivo ++/6 em borda esternal esquerda média. Pulmões com ausculta simétrica sem ruídos adventícios. Abdome sem alterações. Pulsos simétricos e saturação periférica de $96 \%$.

\section{ELETROCARDIOGRAMA}

Ritmo com pausa sinusal e escape atrial em D2, freqüência de 85 bat/min, eixo elétrico do complexo QRS indeterminado. Dupla positividade do QRS em V1, indicando bloqueio de ramo direito de grau leve a moderado (Figura 1).

\section{RADIOGRAMA}

Área cardíaca normal com índice cardiotorácico de 0,45. Proeminência discreta do tronco arterial pulmonar, com tênue lesão de espaço aéreo peribrônquico em bases pulmonares e sinais de proeminência vascular pulmonar.
Serviço de Cirurgia Cardiovascular Pediátrica de São José do Rio Preto - Hospital de Base - Faculdade Estadual de Medicina de São José do Rio Preto

Correspondência: Ulisses Alexandre Croti

Hospital de Base - FAMERP - Avenida Brigadeiro Faria Lima, 5544.

CEP 15090-000 - São José do Rio Preto - São Paulo.

Telefones: 17-97726560 / 32015025 / 32226450.

E-mail: uacroti@uol.com.br

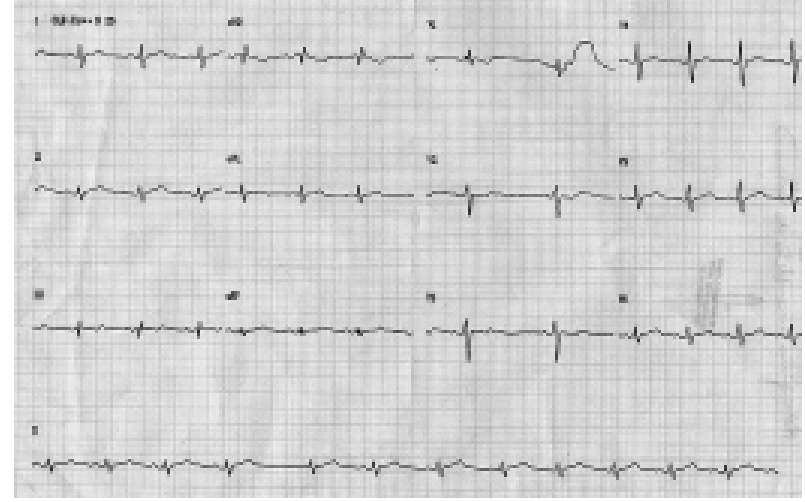

Fig. 1 - Eletrocardiograma pré-operatório

\section{ECOCARDIOGRAMA}

Situs solitus em levocardia. Conexões veno-atrial, átrioventricular e ventrículo-arterial concordantes. Conexão das veias pulmonares no átrio esquerdo caracterizada pelo fluxo das veias pulmonares superiores direcionado para a veia cava superior e átrio direito. Comunicação interatrial tipo seio venoso subcaval de $21 \mathrm{~mm}$ em seu maior eixo. Dilatação do tronco e ramos pulmonares. Ao Doppler havia regurgitação tricúspide discreta, pressão sistólica em ventrículo direito de 39 mmHg e QP/QS de 5,0. 


\section{DIAGNÓSTICODIFERENCIAL}

Deve ser lembrada a dilatação idiopática do tronco pulmonar, janela aortopulmonar, comunicação interatrial, defeito do canal atrioventricular forma parcial, conexão anômala parcial de veias pulmonares e a síndrome de cimitarra.

\section{DIAGNÓSTICO}

Com intuito de confirmar as conexões venosas pulmonares no átrio esquerdo e excluir outras associações, o estudo cineangiocardiográfico foi indicado, demonstrando haver conexão concordante das veias pulmonares no átrio esquerdo. A veia pulmonar superior direita conectava-se ao átrio esquerdo, porém seu fluxo era direcionado ao átrio direito. Assim, confirmando o diagnóstico ecocardiográfico de comunicação interatrial tipo seio venoso superior.
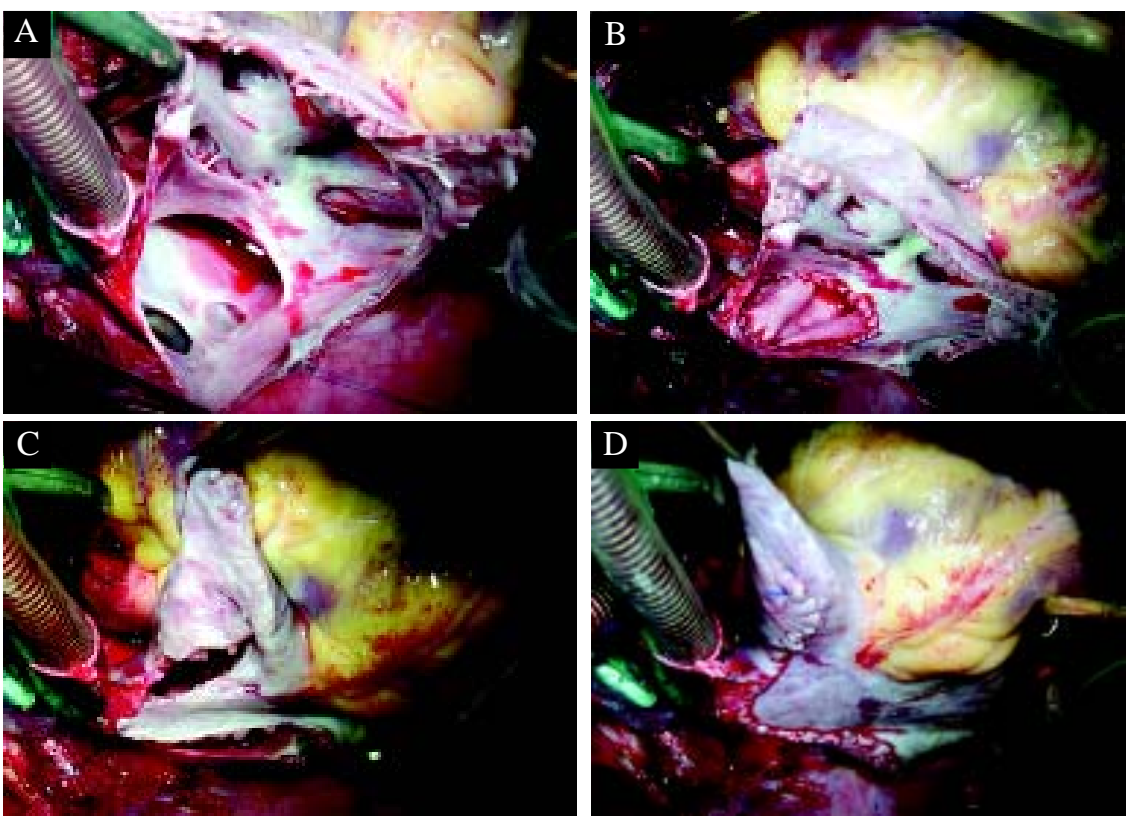

Fig. 2 - A-Átrio direito aberto onde se visibilizam as veias pulmonares direitas drenando no átrio esquerdo e seu fluxo direcionado para a comunicação interatrial tipo seio venoso superior. B - Comunicação interatrial fechada com placa de pericárdio bovino. C e D Ampliação da veia cava superior com o tecido atrial direito aberto em forma de " $V$-Y"

\section{OPERAÇÃO}

Toracotomia mediana transesternal. Instituição do auxílio de circulação extracorpórea com hipotermia a $32^{\circ} \mathrm{C}$. Cardioplegia sangüínea, anterógrada, intermitente, hipotérmica a $4^{\circ} \mathrm{C}$. Oátrio direito foi aberto utilizando-se a técnica de atrioplastia em "VY”, com intuito de ampliar a veia cava superior com tecido da parede atrial direita. A incisão posterior no átrio direito foi continuada em direção à veia cava superior lateralmente, evitando lesão do nó sinusal e de sua artéria. Após localização das quatro veias pulmonares (Figura 2A), foi suturada uma placa de pericárdio bovino, isolando-se as veias pulmonares para o átrio esquerdo (Figura 2B). A veia cava superior foi ampliada com o tecido do próprio átrio direito (atriocavoplastia), como demonstrado na Figura 2C e 2D [1]. O tempo de circulação extracorpórea foi de 80 minutos e de isquemia miocárdica 62 minutos. Um ano após a operação, o paciente apresenta ritmo cardíaco semelhante ao pré-operatório e correção total do defeito sem obstruções venosas ao ecocardiograma. Importante salientar que esta técnica é de extrema utilidade e facilmente reproduzível tanto em portadores de comunicação interatrial tipo seio venoso superior quanto naqueles com conexão anômala parcial de veias pulmonares [2].

\section{REFERÊNCIAS BIBLIOGRÁFICAS}

1. DeLeon SY, Freeman JE, Ilbawi MN, Husayni TS, Quinones JA, Ow EP et al. Surgical techniques in partial anomalous pulmonary veins to the superior vena cava. Ann Thorac Surg. 1993;55(5):1222-6.

2. Dervanian P, Mace L, Puyo P, Folliguet TA, Abdelmoulah S, Santoro $\mathrm{F}$ et al. Techniques of correction of partial right abnormal pulmonary venous return associated with atrial septal defect. Arch Mal Coeur Vaiss. 1996;89(7):857-63.
Correção: Diferentemente do que foi publicado na Correlação 5, página 347 do volume 20.3, os dados corretos são: Qp/Qs de $1,0, \operatorname{RVP} 1,1 \mathrm{~W} / \mathrm{m}^{2}$, RVS 10,9 W/m, RVP/RVS 0,1. 